\title{
A theoretical study on the ground and excited state behaviors of TTBC related carbocyanine dyes
}

\author{
Sila Karaca, Nuran Elmaci * \\ Department of Chemistry, İzmir Institute of Technology, Urla, 35430 Izmir, Turkey
}

\section{A R T I C L E I N F O}

\section{Article history:}

Received 10 August 2009

Received in revised form 26 August 2009

Accepted 26 August 2009

Available online 3 September 2009

\section{Keywords:}

TDDFT

DFT

Cyanine dye

TTBC

$\mathrm{JC}-1$

\begin{abstract}
A B S T R A C T
The effects of functional groups on the benzimidazole rings, length of the conjugated chain and alkyl groups bonded to the nitrogen atoms on the ground and excited state behaviors of the $1,1^{\prime}, 3,3^{\prime}$-tetraethyl-5,5',6,6'-tetrachlorobenzimidazolocarbocyanine (TTBC or JC-1) have been analyzed via quantum chemical methods. DFT and TDDFT with B3LYP/6-31G(d,p) level of theory were used for the ground and excited state calculations, respectively. It has been found that TTBC has a very rigid geometry; no significant effect of functional groups has been predicted either as donor or acceptor on its optimum structure. However, the length of alkyl groups changes the structure of the molecule. It is possible to increase $\lambda_{\text {max }}$ of TTBC based carbocyanine dye with $\mathrm{NH}_{2}$, butyl/propyl and increasing polymethine chain length.
\end{abstract}

(C) 2009 Elsevier B.V. All rights reserved.

\section{Introduction}

In the last decades, interests in cyanine dyes [1] are rapidly increasing due to their wide application areas such as sensitizers in photographic industry [2], laser dyes [3,4], anti-tumor agent [5], non-linear optics [6], optical disk as recording media [7] and fluorescence probe for biological molecules [8].

Mitochondria is a very important organelle in many biological processes. The function of this organelle can be understood clearly by measuring mitochondrial membrane potential $(\Delta \Psi)$. TTBC (JC1 ) is one of the well-known molecular probe to monitor $\Delta \Psi$ which is used to detect a live or death cell $[9,10]$. The chemical structure of cationic TTBC dye is shown in Fig. 1. A high $\Delta \Psi$ (live) cause to form TTBC J-aggregate [11] and the cells fluoresce orange $(590 \mathrm{~nm})$ and at low $\Delta \Psi$ (death) TTBC stays in the monomeric form fluoresce green $(527 \mathrm{~nm})[12]$. The big advantage of TTBC over rhodamines and other carbocyanines is that its color can be changed from green (monomeric form) to orange (aggregate form) depending on whether the cell alive or death [13]. Specific and selective cyanine dyes, which have a different range of absorption and emission wavelengths are very important to detect proteins, nucleic acids, other biological and non-biological materials [14]. So the synthesis of different selective cyanine dyes is under development.

The aim of this study is to examine the ground and excited state behaviors of the cyanine dyes; TTBC related compounds by using of

\footnotetext{
* Corresponding author. Tel.: +90 232750 7532; fax: +90 2327507509 .

E-mail address: nuranelmaci@iyte.edu.tr (N. Elmacı).
}

quantum chemical methods. The effect of functional groups attached to benzene rings, the alkyl size bonded to nitrogens and the length of polymethine chain have been investigated to give an insight into new design of similar dyes as molecular labels in biochemical applications.

There are many theoretical studies which show that Time Dependent Density Functional Theory (TDDFT) [15-17] allow to simulate correctly UV-Vis spectra of organic dyes [18-24]. Although there are some disadvantages of TDDFT reported in the literature (charge transfer [25-27], double excitations [28-30] and Rydberg states [31,32]), it is demonstrated that these can be reduced by the adjustment of the functionals and the combinations of solvation models. Jacquemin and coworkers have been reported that TDDFT maximum absorption wavelengths agree excellently with the experimental ones for a number of dyes [33]. They also studied substitution effect on indigos, thioindigos and diazonium dyes [34-36]. Guillaumont and Nakamura showed that TDDFT correctly reproduces the UV/Vis spectrum of a series of organic dyes [37]. The substitution effect on the absorption spectrum of hemicyanine dyes with pyridine nucleus is studied by Wang et al. [38]. They showed that electron donor substituent increases maximum wavelength on the other hand para and meta substituted $\mathrm{NO}_{2}$ decreases maximum wavelength relative to unsubstituted dye. Bertolino et al. investigated the solvent effect on a series of indocyanine dyes by TDDFT which are in good agreement with the experiments [39]. Very recently, Wang et al. reported a theoretical study on the excited state calculations of the dimethine cyanine dyes [40]. 


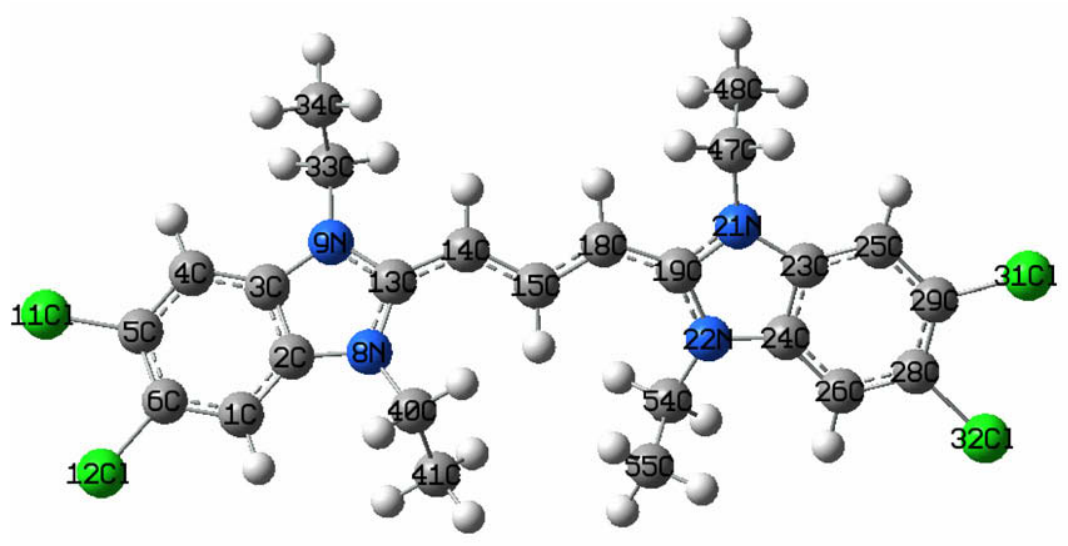

Fig. 1. Cationic structure of TTBC.

\section{Methodology}

All computations have been carried out with Gaussian 03 [41] program. The Density Functional Theory was carried out in the optimization part with the Becke Three Parameter Lee, Yang and Parr B3LYP [42] functional by using 6-31G(d,p) basis set. The frequencies were checked for imaginary eigenvalues to ensure that the optimized structures are energy minimums. Time Dependent Density Functional Theory (TDDFT) has been used for the excited state calculations on the ground state structures. The first 15 vertical singlet excited states were computed by using TDDFT/ B3LYP/6-31G(d,p) on the optimized geometries. The iodide ion (counter ion) of the TTBC has been ignored in all calculations. The overall charge of the molecule is $(+1)$.

\section{Results}

\subsection{Optimization part of TTBC}

The calculated and experimental geometrical parameters are given in Table 1 . We have carried out a linear regression analysis to compare optimized structure with the X-ray structure [43], the correlation coefficient was found as 0.9894 for bond lengths and 0.9813 for bond angles. The mean absolute error is 0.0115 and 0.7728 for the bond lengths and angles, respectively. The maximum percent relative error is 3.10 for the bond length at C40C41 and 3.35 for C48-C47-N21 bond angle. These atoms are in

Table 1

Some selected bond lengths and angles of TTBC

\begin{tabular}{|c|c|c|c|c|c|}
\hline \multicolumn{3}{|c|}{ Bond lengths $(\AA)$} & \multicolumn{3}{|l|}{ Bond angles $\left({ }^{\circ}\right)$} \\
\hline Atoms & DFT & X-ray & Atoms & DFT & X-ray \\
\hline$C(1)-C(2)$ & 1.3894 & 1.3747 & $N(8)-C(2)-C(1)$ & 131.4 & 131.2 \\
\hline$C(2)-C(3)$ & 1.4007 & 1.3840 & $N(9)-C(33)-C(34)$ & 113.1 & 109.5 \\
\hline$C(3)-C(4)$ & 1.3899 & 1.3914 & $N(9)-C(13)-N(8)$ & 107.1 & 107.2 \\
\hline$C(4)-C(5)$ & 1.3980 & 1.3796 & $N(9)-C(3)-C(4)$ & 131.7 & 131.0 \\
\hline$C(5)-C(6)$ & 1.4115 & 1.3876 & $\mathrm{Cl}(11)-\mathrm{C}(5)-\mathrm{C}(6)$ & 121.0 & 119.5 \\
\hline$C(6)-C(1)$ & 1.3982 & 1.3846 & $\mathrm{Cl}(11)-\mathrm{C}(5)-\mathrm{C}(4)$ & 118.0 & 118.2 \\
\hline $\mathrm{C}(5)-\mathrm{Cl}(11)$ & 1.7392 & 1.7383 & $C(15)-C(18)-C(19)$ & 129.9 & 129.1 \\
\hline $\mathrm{C}(6)-\mathrm{Cl}(12)$ & 1.7396 & 1.7293 & $C(15)-C(14)-C(13)$ & 129.9 & 129.6 \\
\hline $\mathrm{C}(2)-\mathrm{N}(8)$ & 1.3956 & 1.3927 & $\mathrm{C}(14)-\mathrm{C}(13)-\mathrm{N}(8)$ & 130.2 & 130.8 \\
\hline$N(8)-C(13)$ & 1.3764 & 1.3635 & $N(8)-C(13)-C(14)-C(15)$ & 19.6 & 5.1 \\
\hline$N(9)-C(13)$ & 1.3777 & 1.3717 & & & \\
\hline$N(9)-C(3)$ & 1.3909 & 1.3886 & & & \\
\hline$N(9)-C(33)$ & 1.4674 & 1.4567 & & & \\
\hline $\mathrm{N}(8)-\mathrm{C}(40)$ & 1.4651 & 1.4634 & & & \\
\hline$C(13)-C(14)$ & 1.4093 & 1.3944 & & & \\
\hline$C(14)-C(15)$ & 1.3957 & 1.3797 & & & \\
\hline
\end{tabular}

the ethyl groups. B3LYP/6-31G ${ }^{* *}$ level of theory overestimates the C40-C41 bond length by 0.046 and C48-C47-N21 bond angle by 3.67 and the largest discrepancies between X-ray and computed structure are seen in the ethyl moieties. Ethyl groups bonded to N9 and N22 atoms are in up position while the other two ethyls bonded to N8 and N21 atoms are in down position from the molecular plane (Fig. 1). However, in the X-ray structure ethyls in N8, N9 are in up and in N21, N22 are in down position. We have performed optimizations by changing the orientations of the ethyl groups. It was observed that, these groups can easily rotate with almost no significant energy change.

The bond lengths along the backbone are about $1.400 \AA$ which is in between single and double bonds of carbon that reflects the conjugation on the molecular plane. The size of the TTBC is about $17.5 \AA \times 8.8 \AA$ (X-ray length $=17.4 \AA \times 8.1 \AA$ ) and the deviation from the planarity is $19.6^{\circ}$. Although the bond lengths are in good agreement with the experiment the dihedral angle differ by $15^{\circ}$ which might be due to the crystal packing effect. These results reveal that B3LYP/6-31G ${ }^{* *}$ level of theory is suitable for the description of the geometric structure of TTBC without sacrificing much accuracy.

NBO (Natural Bond Orbital) and Mulliken charges were used for the charge analysis. The molecule was divided into seven charge groups. These groups are shown in Fig. 2a by circles with group numbers. The groups are four alkyls $(1,3,4,6)$, two benzimidazoles $(2,5)$ and one polymethine chain (7). The charges of these groups are shown in Fig. 2, where the charge of each atom is visualized in color scale. The color scale changes from red (most negative) to green (most positive). The most negative atoms are nitrogens while their carbon neighbors bonded to polymethine chain hold the most positive charge. The alkyl groups are carrying all positive charges while polymethine chain is negatively charged and the benzimidazole rings have almost zero charge according to both Mulliken and NBO charge analysis. But the magnitudes of the charges are different in each method. Alkyl groups have similar charges in both methods however the charge on polymethine chain is almost doubled in NBO method.

The HOMO-LUMO shapes are given in Fig. 3. There is no electron distribution on the ethyl groups and the electrons spreads out on the backbone of the molecule. The HOMO-LUMO pictures show that the electrons are migrated from $\mathrm{Cl}$ atoms to the molecule. Chlorine atoms act as electron donor.

\subsection{Side group effects on the TTBC}

The quantum mechanical calculations can play an important role to design new versatile functional dyes with tuned optical and spectral properties. In this part, the ground and excited state 

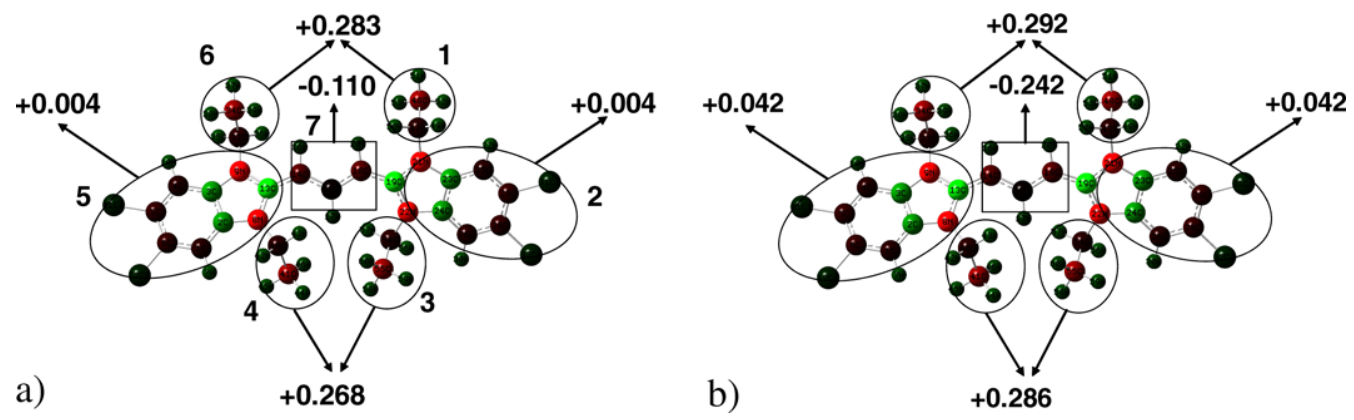

Fig. 2. (a) Mulliken charges of TTBC, (b) NBO charges of TTBC.

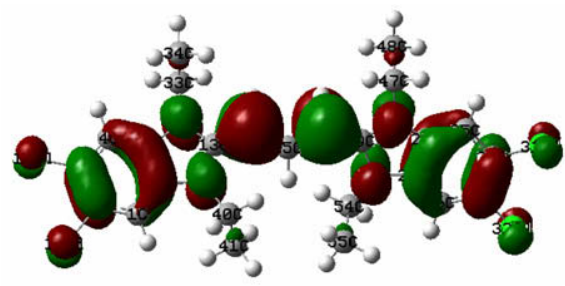

HOMO of TTBC

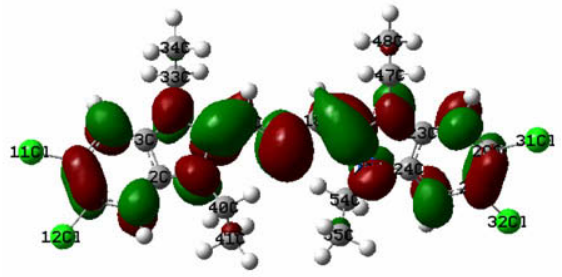

LUMO of TTBC

Fig. 3. HOMO and LUMO of TTBC.<smiles>[R]c1cc2c(cc1[R2])N(CC)C(=C/C=C/c1n(CC)c3cc([R6])c([R4])cc3[n+]1CC)N2CC</smiles>

Fig. 4. TTBC related dye.

behaviors of the TTBC related dyes in the gas phase have been examined by using quantum chemical methods. TTBC related dyes are defined by (1) substitution donor/acceptor (D/A) moieties instead of chlorine atoms, (2) changing the size of alkyl groups, (3) altering the length of the polymethine chain in the TTBC dye.

\subsubsection{Effect of donor-acceptor side groups}

We used different functional groups on the terminal benzene rings to investigate how electron activating and deactivating groups change the electronic and spectral properties of the TTBC dye. These cyanine dye derivatives with various $\mathrm{D} / \mathrm{A}$ substituents $\left(R_{1}, R_{2}, R_{3}, R_{4}\right)$ are shown in Fig. 4 and Table 2 .

The bond lengths of the molecule are almost identical. The most affected bond length was decreased from the donor to acceptor substituted dye about $0.03 \AA$ except for -CN (Table 3).

Table 2

Cyanine dye derivatives with different side groups.

\begin{tabular}{lllll}
\hline Dye derivatives & $\mathrm{R}_{1}$ & $\mathrm{R}_{2}$ & $\mathrm{R}_{3}$ & $\mathrm{R}_{4}$ \\
\hline $1 \mathrm{R}$ & $\mathrm{R}$ & $\mathrm{H}$ & $\mathrm{H}$ & $\mathrm{H}$ \\
$2 \mathrm{R}$ & $\mathrm{R}$ & $\mathrm{R}$ & $\mathrm{H}$ & $\mathrm{H}$ \\
$2 \mathrm{R}-1$ & $\mathrm{R}$ & $\mathrm{H}$ & $\mathrm{R}$ & $\mathrm{H}$ \\
$2 \mathrm{R}-2$ & $\mathrm{H}$ & $\mathrm{R}$ & $\mathrm{H}$ & $\mathrm{R}$ \\
$2 \mathrm{R}-3$ & $\mathrm{R}$ & $\mathrm{H}$ & $\mathrm{H}$ & $\mathrm{R}$ \\
$2 \mathrm{R}-4$ & $\mathrm{H}$ & $\mathrm{R}$ & $\mathrm{R}$ & $\mathrm{H}$ \\
$3 \mathrm{R}$ & $\mathrm{R}$ & $\mathrm{R}$ & $\mathrm{R}$ & $\mathrm{H}$ \\
$4 \mathrm{R}$ & $\mathrm{R}$ & $\mathrm{R}$ & $\mathrm{R}$ & $\mathrm{R}$ \\
\hline
\end{tabular}

The dihedral angles (N8-C13-C14-C15) decrease from the donor substituted dye to the acceptor substituted dye slightly (Fig. 5). The largest difference of the twist angle is in between $-\mathrm{NH}_{2}$ and $-\mathrm{NO}_{2}$ substituted molecule (about $5^{\circ}$ ). So adding of the activating and deactivating groups do not impact the planarity of the molecule.

The Mulliken atomic charges of the groups were displayed in Fig. 6. Electron donor moieties increased the charge on benzimidazole rings but decreased the charge on the rest of the molecule with respect to TTBC. The opposite case is observed with the acceptor groups. When we introduced only one $\mathrm{D} / \mathrm{A}(1 \mathrm{R})$ unit, the most effected group is the benzimidazole ring to which the $\mathrm{R}$ group attached, it becomes more positive/negative compared to $\mathrm{Cl}$ substituted dye (Fig. 6a). For the dye derivatives with two D/A's five isomers given in Table 2 are considered. If two $\mathrm{D} / \mathrm{A}(2 \mathrm{R})$ added to the same ring then the same effect is observed more strongly (Fig. 6b). On the other hand if three D/A (3R, two of them are in the same ring) are joined to the molecule, in addition to benzimidazole rings, alkyl groups near to the two D/As attached ring are slightly effected too (Fig. 6c). When all of the side groups (4R case) are acceptors then the benzimidazole groups ( 2 and 5 ) becomes slightly negative but still most close to zero, ethyl groups $(1,3,4$, 6 ) are more positive and chain (7) less negative. On the other hand, if the side groups are donors then benzimidazole groups are more positive, ethyl groups are less positive and chain is more negative with respect to the TTBC molecule (Fig. 6d).

In Table 4, the dipole moments of dye derivatives show that the donor groups play minor role whereas acceptor groups significantly affect the dipole moment of dye molecule. The magnitude of the dipoles depends on the number of acceptor units and their positions. If two acceptors are located on the same side then one of the benzimidazole rings becomes more positive while the other one becomes more negative. The opposite case is observed with the donors but the absolute charge difference between two benzimidazole rings with $\mathrm{NH}_{2}$ 's is half of with the $\mathrm{NO}_{2}$ groups. The charge difference between two rings decreases from $\mathrm{NO}_{2}$ substituted dye compared to TTBC (Fig. 6b).

HOMO, LUMO energy levels of $1 R, 2 R, 3 R$ and $4 R$ are displayed in Fig. 7. Both HOMO and LUMO energies decreased from donor to 
Table 3

Geometrical parameters of the cyanine dye derivatives with $4 R$.

\begin{tabular}{|c|c|c|c|c|c|c|}
\hline Atoms & $4 \mathrm{NH}_{2}$ & $4 \mathrm{OCH}_{3}$ & $4 \mathrm{CH}_{3}$ & $4 \mathrm{Cl}$ & $4 \mathrm{CN}$ & $4 \mathrm{NO}_{2}$ \\
\hline$C(1)-C(2)$ & 1.3953 & 1.3966 & 1.3923 & 1.3894 & 1.3887 & 1.3902 \\
\hline$C(2)-C(3)$ & 1.3958 & 1.3951 & 1.3966 & 1.4007 & 1.4047 & 1.4035 \\
\hline$C(3)-C(4)$ & 1.3951 & 1.3947 & 1.3926 & 1.3899 & 1.3896 & 1.3914 \\
\hline$C(4)-C(5)$ & 1.3965 & 1.3921 & 1.3988 & 1.3980 & 1.4025 & 1.3913 \\
\hline$C(5)-C(6)$ & 1.4302 & 1.4276 & 1.4220 & 1.4115 & 1.4225 & 1.4042 \\
\hline$C(6)-C(1)$ & 1.3966 & 1.3988 & 1.3991 & 1.3982 & 1.4030 & 1.3919 \\
\hline $\mathrm{C}(2)-\mathrm{N}(8)$ & 1.3996 & 1.3983 & 1.3988 & 1.3956 & 1.3919 & 1.3908 \\
\hline $\mathrm{N}(8)-\mathrm{C}(13)$ & 1.3757 & 1.3774 & 1.3754 & 1.3764 & 1.3775 & 1.3778 \\
\hline$N(9)-C(13)$ & 1.3754 & 1.3749 & 1.3765 & 1.3777 & 1.3792 & 1.3797 \\
\hline $\mathrm{N}(9)-\mathrm{C}(3)$ & 1.3950 & 1.3942 & 1.3942 & 1.3909 & 1.3870 & 1.3856 \\
\hline$C(13)-C(14)$ & 1.4124 & 1.4112 & 1.4110 & 1.4093 & 1.4078 & 1.4077 \\
\hline$C(14)-C(15)$ & 1.3958 & 1.3958 & 1.3956 & 1.3957 & 1.3960 & 1.3959 \\
\hline $\mathrm{C}(14)-\mathrm{C}(13)-\mathrm{N}(8)$ & 129.9 & 130.1 & 130.2 & 130.2 & 130.3 & 130.3 \\
\hline$N(8)-C(13)-C(14)-C(15)$ & 24.3 & 21.0 & 20.3 & 19.6 & 18.9 & 18.9 \\
\hline
\end{tabular}

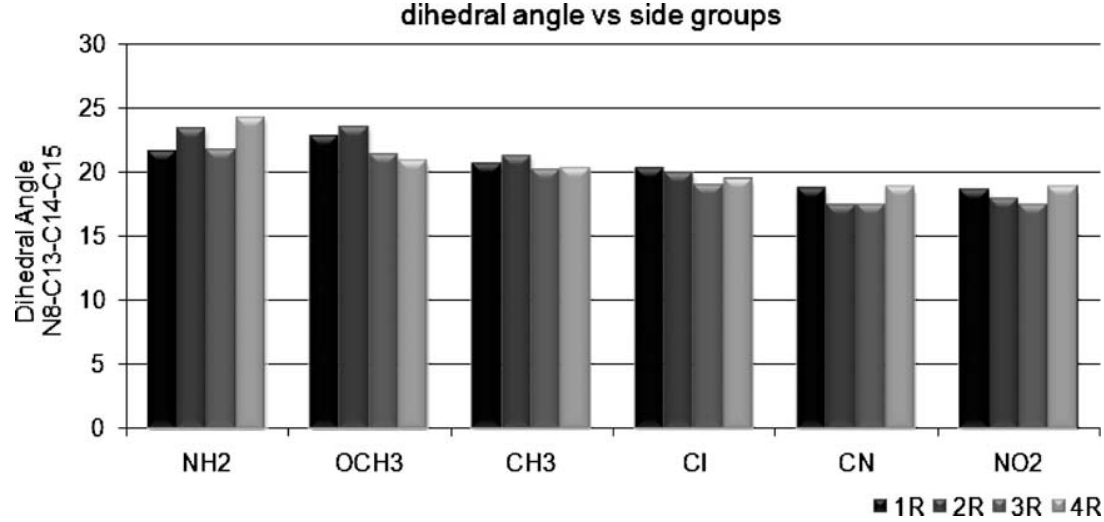

Fig. 5. Dihedral angle of the cyanine dyes with different side groups

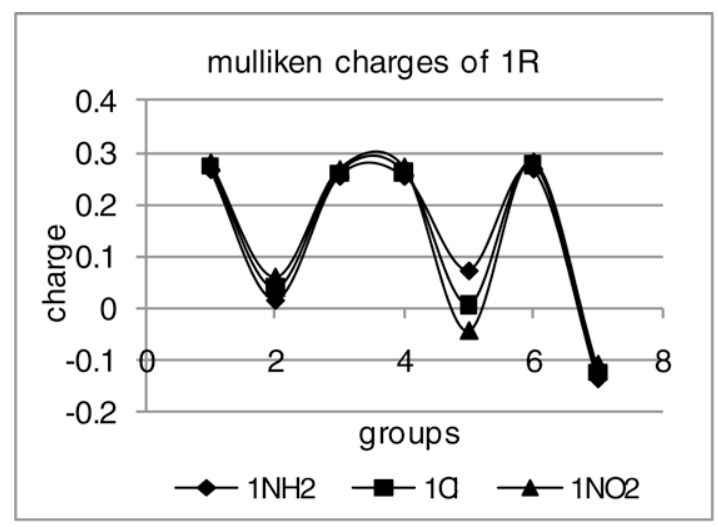

a)

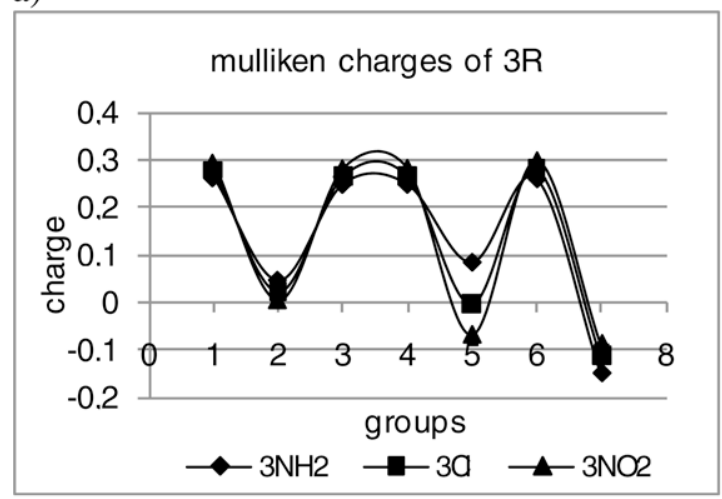

c)

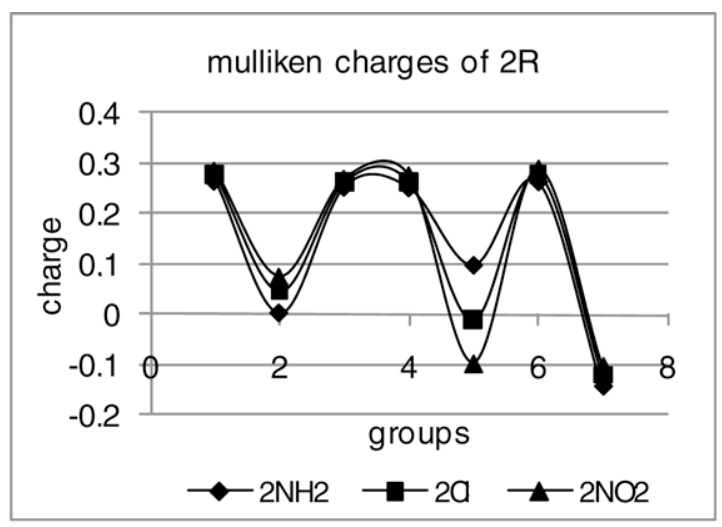

b)

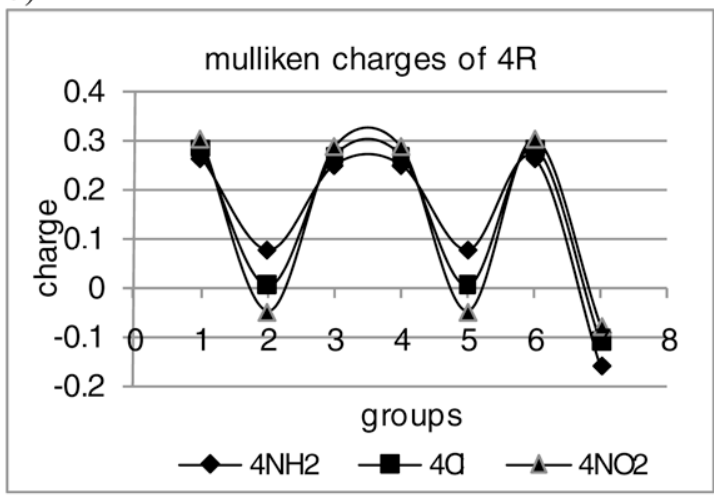

d)

Fig. 6. Mulliken charges of the dye derivatives (a) $1 R$, (b) $2 R$, (c) $3 R$, (d) $4 R$. 
Table 4

Dipole moments of $1 R, 2 R, 2 R$ isomers, $3 R, 4 R$

\begin{tabular}{lclllclc}
\hline Dyes & Dipoles & Dyes & Dipoles & Dyes & Dipoles & Dyes & Dipoles \\
\hline $1 \mathrm{NH}_{2}$ & 1.9 & $2 \mathrm{OCH}_{3}-1$ & 0.4 & $2 \mathrm{Cl}-3$ & 2.5 & $3 \mathrm{NH}_{2}$ & 1.1 \\
$1 \mathrm{OCH}_{3}$ & 1.7 & $2 \mathrm{OCH}_{3}-2$ & 1.5 & $2 \mathrm{Cl}-4$ & 2.5 & $3 \mathrm{OCH}_{3}$ & 3.0 \\
$1 \mathrm{CH}_{3}$ & 0.7 & $2 \mathrm{CCH}_{3}-3$ & 1.1 & $2 \mathrm{CN}$ & 14.9 & $3 \mathrm{CH}_{3}$ & 0.8 \\
$1 \mathrm{Cl}$ & 5.2 & $2 \mathrm{OCH}_{3}-4$ & 1.1 & $2 \mathrm{CN}-1$ & 8.0 & $3 \mathrm{Cl}$ & 5.8 \\
$1 \mathrm{CN}$ & 8.4 & $2 \mathrm{CH}_{3}$ & 1.0 & $2 \mathrm{CN}-2$ & 0.8 & $3 \mathrm{CN}$ & 10.2 \\
$1 \mathrm{NO}_{2}$ & 10.5 & $2 \mathrm{CH}_{3}-1$ & 0.6 & $2 \mathrm{CN}-3$ & 4.2 & $3 \mathrm{NO}_{2}$ & 11.3 \\
$2 \mathrm{NH}_{2}$ & 1.8 & $2 \mathrm{CH}_{3}-2$ & 0.4 & $2 \mathrm{CN}^{2} 4$ & 4.2 & $4 \mathrm{NH}_{2}$ & 0.3 \\
$2 \mathrm{NH}_{2}-1$ & 0.5 & $2 \mathrm{CH}_{3}-3$ & 0.5 & $2 \mathrm{NO}_{2}$ & 17.7 & $4 \mathrm{OCH}_{3}$ & 2.5 \\
$2 \mathrm{NH}_{2}-2$ & 0.1 & $2 \mathrm{CH}_{3}-4$ & 0.5 & $2 \mathrm{NO}_{2}-1$ & 9.1 & $4 \mathrm{CH}_{3}$ & 0.6 \\
$2 \mathrm{NH}_{2}-3$ & 2.0 & $2 \mathrm{Cl}^{2}$ & 9.1 & $2 \mathrm{NO}_{2}-2$ & 0.9 & $4 \mathrm{Cl}^{2}$ & 3.5 \\
$2 \mathrm{NH}_{2}-4$ & 2.0 & $2 \mathrm{Cl}-1$ & 4.5 & $2 \mathrm{NO}_{2}-3$ & 4.8 & $4 \mathrm{CN}$ & 6.1 \\
$2 \mathrm{OCH}_{3}$ & 3.6 & $2 \mathrm{Cl}-2$ & 0.0 & $2 \mathrm{NO}_{2}-4$ & 4.8 & $4 \mathrm{NO}_{2}$ & 6.6 \\
\hline
\end{tabular}

acceptor groups. Chloro unit is the weakest acceptor. HOMO and LUMO energies increased by electron donors and decreased by electron acceptors relative to TTBC which support Wang et al.'s work for stryl dyes [44].

Adding $2 \mathrm{R}$ groups to different rings did not affect the HOMOLUMO energies and the gap between them. Both HOMO and LUMO energies increased from the dye with acceptor to the dye with donor groups (Fig. 8).

When one $\mathrm{D} / \mathrm{A}$ unit is bonded to benzimidazole ring, the most strongest $\mathrm{D} / \mathrm{A}$ increases $\lambda_{\max }$ about $15-20 \mathrm{~nm}$ with respect to moderate ones whereas adding two units of $\mathrm{D} / \mathrm{A}$ on the same ring, $\lambda_{\max }$ increased for $\mathrm{NH}_{2}$, decreased for $\mathrm{NO}_{2}$ and moderates are not affected. Substituting one of the $\mathrm{NO}_{2}$ group on the next ring increased the wavelength about $20 \mathrm{~nm}$ (Fig. 9).

When $2 \mathrm{R}$ groups attached to the different benzimidazole ring, $\lambda_{\max }$ values are almost the same except $\mathrm{NO}_{2}$. On the other hand, if $\mathrm{NO}_{2}$ groups were bonded to the same side then $\lambda_{\max }$ decreased due to the strong electron withdrawing effect (Fig. 10). In that case excitation to the first excited state is mainly $\mathrm{H} \rightarrow \mathrm{L}+1$ (a charge transfer state; $\lambda_{\max }=441 \mathrm{~nm} ; f=0.053$ ) with a very small oscillator strength $(f)$ but the excitation to the second excited state is characterized by $\mathrm{H} \rightarrow \mathrm{L}\left(\lambda_{\max }=425 \mathrm{~nm} ; f=1.662\right)$.

For 3Rs and 4Rs there is a red shift in $\lambda_{\max }$ for the dyes with both donors and acceptors with respect to $\mathrm{Cl}$ and $\mathrm{CH}_{3}$ substituted ones however the shift is much larger in the donor side (Fig. 9). The absorption $\lambda_{\max }$ increases with increasing number of the same substituents except for $\mathrm{NO}_{2}$, again much larger change observed for donors. Wang et al. reported that para substituted electron donor

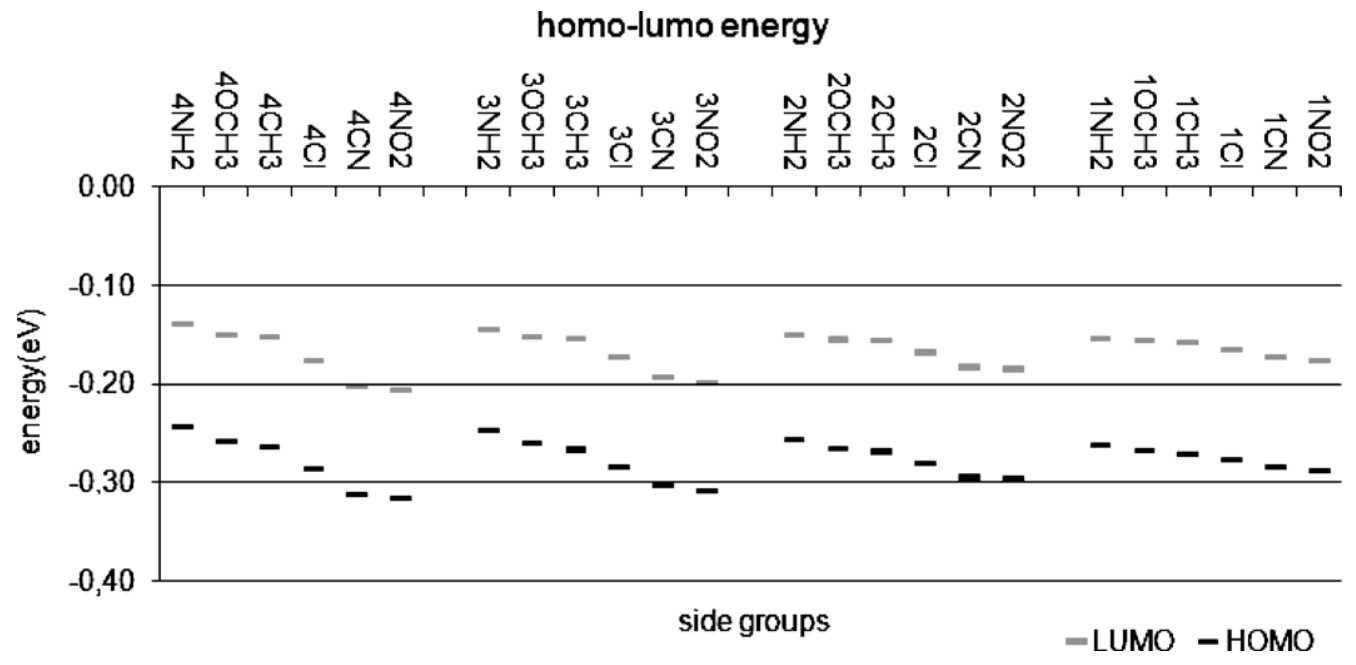

Fig. 7. HOMO-LUMO energy levels of $1 R, 2 R, 3 R, 4 R$.

homo-lumo energy

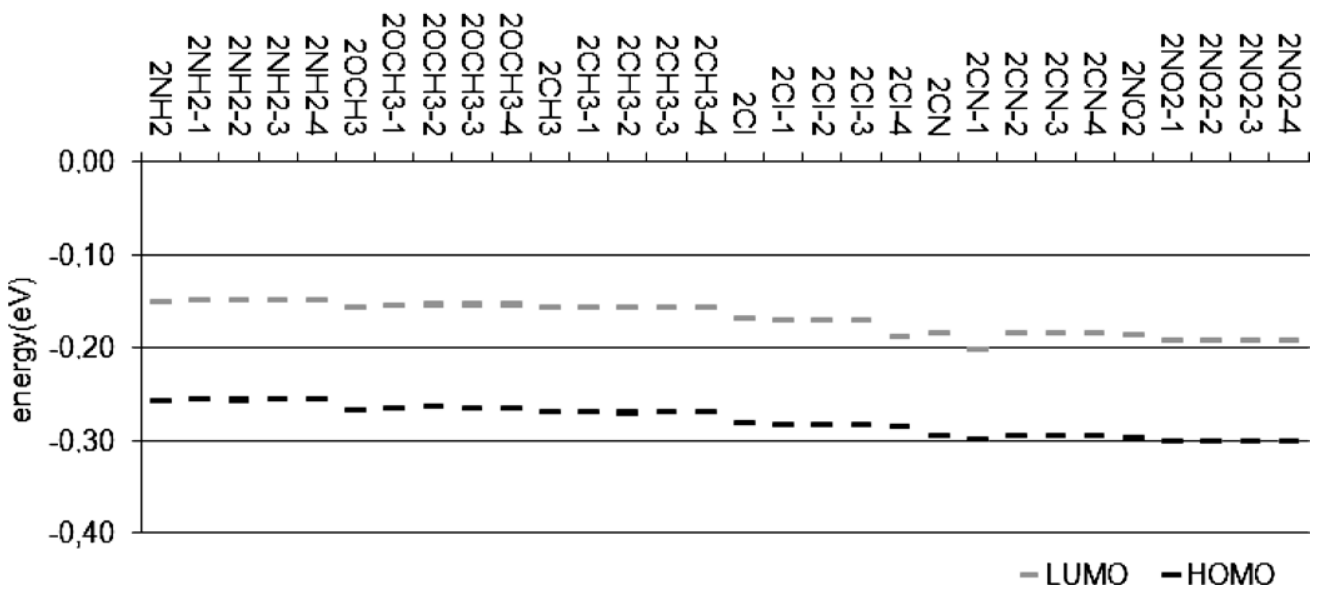

Fig. 8. HOMO-LUMO energy levels of $2 \mathrm{R}$ isomers. 


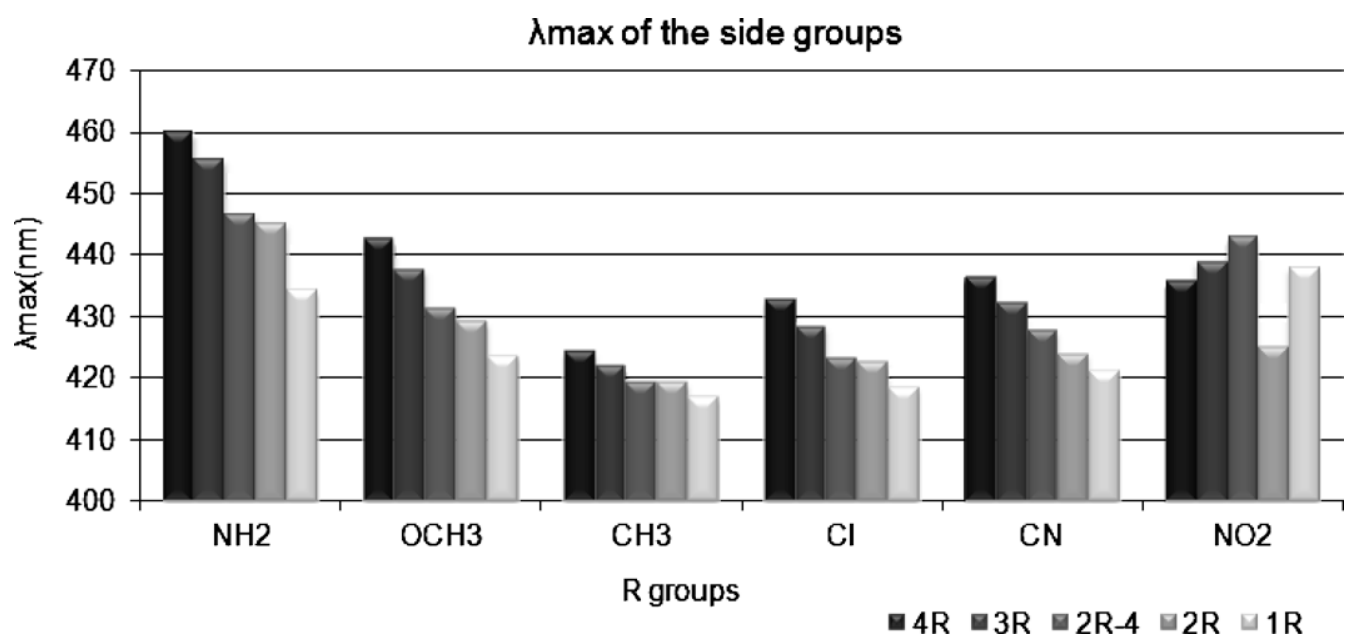

Fig. 9. $\lambda_{\max }$ for $1 R, 2 R, 3 R, 4 R$.

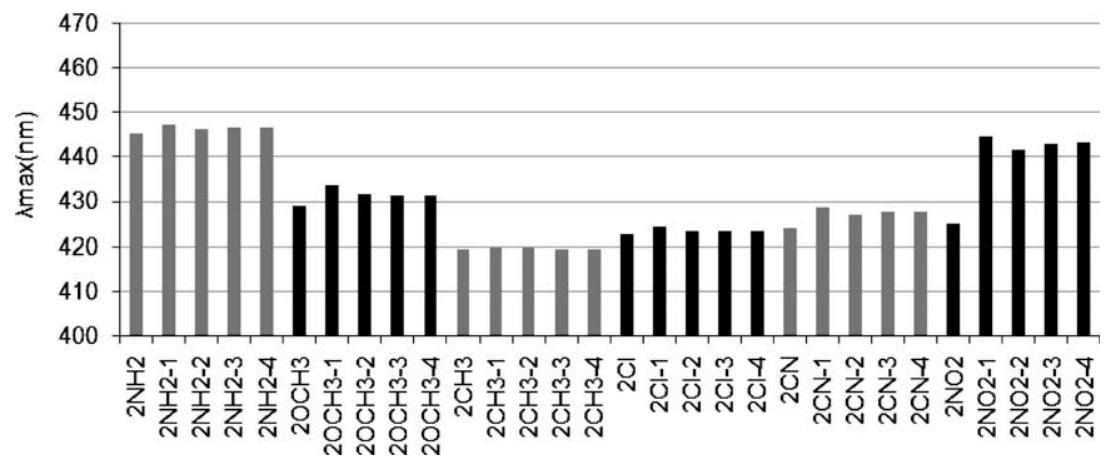

Fig. 10. $\lambda_{\max }$ for $2 R$ isomers.

groups at the end of benzene ring make $\lambda_{\max }$ longer by joining molecular conjugation for hemicyanine dyes with pyridine nucleus and stryl dyes with quinoline nucleus both theoretically and experimentally. However, $\mathrm{NO}_{2}$ substituent blue shifted $\lambda_{\max }$ in meta position and red shifted $\lambda_{\max }$ in para position for stryl dyes $[38,44]$.

Table 5

The excited state compositions, oscillator strengths and $\lambda_{\max }$ of $4 \mathrm{R}$.

\begin{tabular}{lllcll}
\hline $\begin{array}{l}\mathrm{R} \\
\text { groups }\end{array}$ & $\begin{array}{l}\text { Exc. } \\
\text { state }\end{array}$ & $\begin{array}{l}\text { Transition } \\
\text { character }\end{array}$ & $\begin{array}{l}\text { Transition } \\
\text { probability }\end{array}$ & $\begin{array}{l}\text { Oscillator } \\
\text { strength }\end{array}$ & $\begin{array}{l}\lambda_{\max } \\
(\mathrm{nm})\end{array}$ \\
\hline $4 \mathrm{NH}_{2}$ & $\mathrm{~S}_{1}$ & $\mathrm{H} ; \mathrm{L}^{\mathrm{a}}$ & 0.63 & 1.69 & 460 \\
& $\mathrm{~S}_{2}$ & $\mathrm{H}-1 ; \mathrm{L}$ & 0.66 & 0.01 & 369 \\
& & $\mathrm{H} ; \mathrm{L}+1$ & -0.20 & & \\
$40 \mathrm{CH}_{3}$ & $\mathrm{~S}_{1}$ & $\mathrm{H} ; \mathrm{L}$ & 0.62 & 1.82 & 443 \\
& $\mathrm{~S}_{2}$ & $\mathrm{H}-1 ; \mathrm{L}$ & 0.64 & 0.00 & 337 \\
& & $\mathrm{H} ; \mathrm{L}+1$ & -0.25 & & \\
$4 \mathrm{CH}_{3}$ & $\mathrm{~S}_{1}$ & $\mathrm{H} ; \mathrm{L}$ & 0.62 & 1.83 & 424 \\
& $\mathrm{~S}_{2}$ & $\mathrm{H}-1 ; \mathrm{L}$ & 0.58 & 0.00 & 307 \\
& & $\mathrm{H} ; \mathrm{L}+1$ & 0.40 & & \\
$4 \mathrm{Cl}$ & $\mathrm{S}_{1}$ & $\mathrm{H} ; \mathrm{L}$ & 0.62 & 1.89 & 433 \\
& $\mathrm{~S}_{2}$ & $\mathrm{H}-1 ; \mathrm{L}$ & 0.58 & 0.00 & 320 \\
& & $\mathrm{H} ; \mathrm{L}+1$ & 0.40 & & \\
$4 \mathrm{CN}$ & $\mathrm{S}_{1}$ & $\mathrm{H} ; \mathrm{L}$ & 0.62 & 2.02 & 437 \\
& $\mathrm{~S}_{2}$ & $\mathrm{H}-2 ; \mathrm{L}$ & -0.12 & 0.01 & 346 \\
$4 \mathrm{NO}_{2}$ & $\mathrm{~S}_{1}$ & $\mathrm{H} ; \mathrm{L}+2$ & 0.68 & & \\
& $\mathrm{~S}_{2}$ & $\mathrm{H} ; \mathrm{L}+\mathrm{L}+1$ & 0.62 & 1.86 & 436 \\
& & $\mathrm{H} ; \mathrm{L}+2$ & -0.68 & 0.03 & 408 \\
\end{tabular}

${ }^{\text {a }} \mathrm{H}$ and $\mathrm{L}$ refer to HOMO and LUMO, oscillator strengths are in arbitrary units.
The transition character with their transition probabilities, oscillator strengths and $\lambda_{\max }$ values are given in Table 5 for the first two excited states only for 4Rs. For all substituents the main contributions to the first excited state are coming from $\mathrm{H} \rightarrow \mathrm{L}$ with large oscillator strengths. The second excited state transition is formed by a major $\mathrm{H}-1 \rightarrow \mathrm{L}$ and a minor $\mathrm{H} \rightarrow \mathrm{L}+1$ for donors including $\mathrm{Cl}$. For acceptors $\mathrm{H}-2 \rightarrow \mathrm{L}, \mathrm{H} \rightarrow \mathrm{L}+1$ and $\mathrm{H} \rightarrow \mathrm{L}+2$ are the most participated orbitals. $\mathrm{H} \rightarrow \mathrm{L}+2$ and $\mathrm{H} \rightarrow \mathrm{L}+1$ are the dominant ones for $\mathrm{CN}$ and $\mathrm{NO}_{2}$ substituted dyes, respectively. The intensities of the second transitions are very small.

Fig. 11 displays HOMO-LUMO electron densities for 4Rs. A nice electron conjugation is seen in HOMO-LUMO electron densities. The electron $\mathrm{D} / \mathrm{A}$ properties that is electron transfer from donor to molecule or molecule to acceptor are observed in those figures as expected for the strongest D/As. However, there is no electron density on $\mathrm{CH}_{3}$ units in both HOMO and LUMO and CNs do not act as an electron acceptor (Fig. 11).

\subsubsection{Effect of polymethine chain length}

In this section, the chain length of polymethine group effect on the ground and excited state properties were investigated. Elongation of the chain length (Fig. 12), did not change the bond lengths and angles much, therefore the geometry of the molecule remains almost same. The twist angle between two benzimidazole rings only varies about $2^{\circ}$ from the polymethine chain with nine carbon to three carbon atoms (Table 6).

The total charge of the benzimidazole groups became slightly negative and total charge of polymethine chain increased from $n=3$ to $n=9$ carbon chain and the charge of the ethyl groups were not 


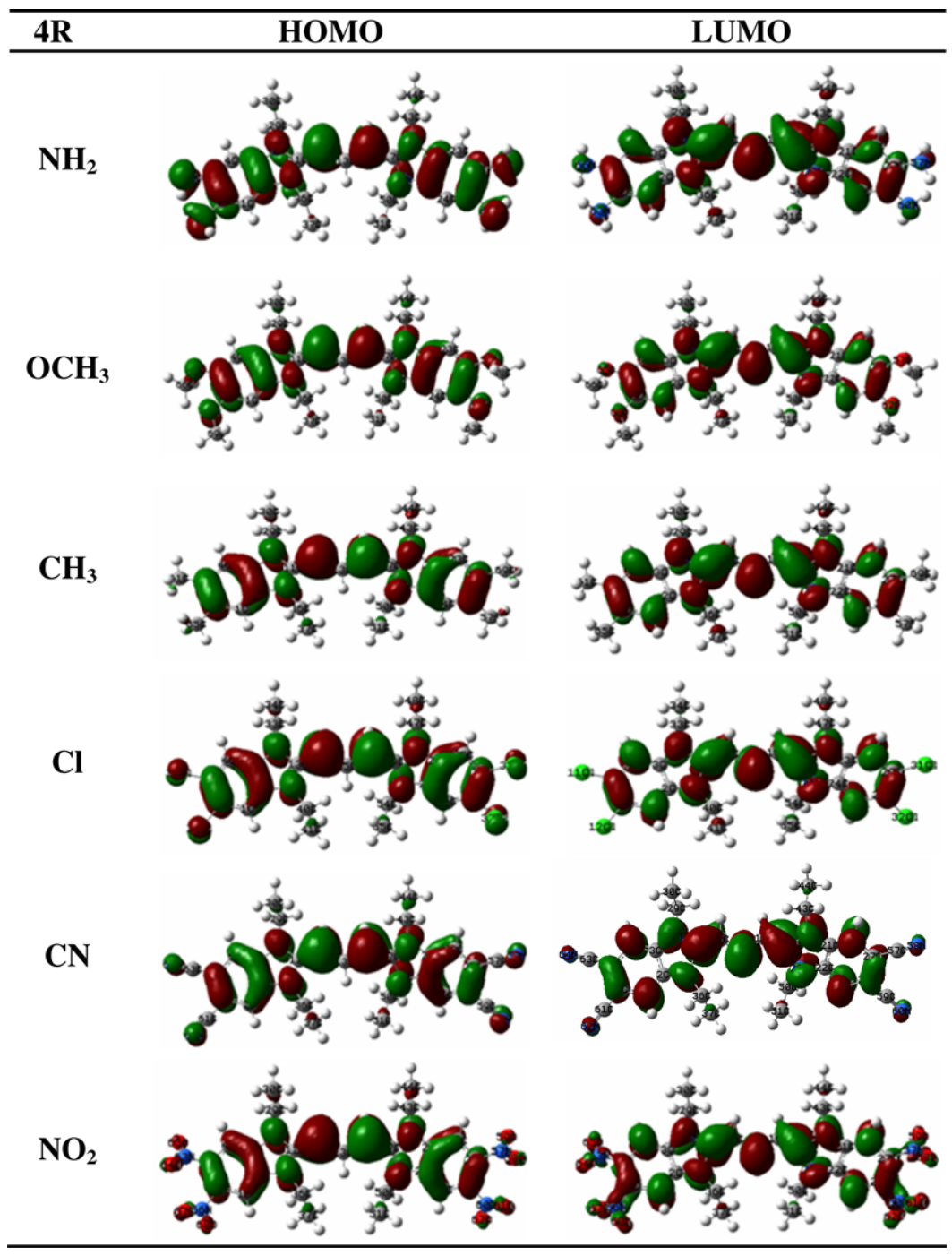

Fig. 11. HOMO-LUMO figures of $4 R$.<smiles>CCN1C(=CC(C)C)N(CC)c2cc(Cl)c(Cl)cc21</smiles>

Fig. 12. Length of the polymethine chain.

affected. The total charge on benzimidazole is almost zero. Increasing the size of polymethine chain increases the charge on polymethine chain twice as magnitude from 3 to 9 carbon atoms (Table 7).

According to Fig. 13, HOMO energies destabilized with the lengthening the polymethine chain while LUMO energies almost remain same. The HOMO-LUMO gap decreases from $n=3$ to $n=9$ by the influence of HOMO energies. Therefore, $\lambda_{\max }$ values shifted to longer wavelengths.

The excited state calculations showed that, wavelength of the first excited state of the molecule was red shifted about $50 \mathrm{~nm}$ for each addition of $\mathrm{C}_{2} \mathrm{H}_{4}$ group (Table 8 ). Conjugation of the molecule increases and a bathochromic shift is observed. The similar results also observed in experimental studies; increasing the
Table 6

Geometrical parameters of the dye derivatives with different polymethine chain.

\begin{tabular}{lllll}
\hline Atoms & $n=3$ & $n=5$ & $n=7$ & $n=9$ \\
\hline $\mathrm{C}(1)-\mathrm{C}(2)$ & 1.3894 & 1.3895 & 1.3894 & 1.3893 \\
$\mathrm{C}(2)-\mathrm{C}(3)$ & 1.4007 & 1.4015 & 1.4019 & 1.4021 \\
$\mathrm{C}(3)-\mathrm{C}(4)$ & 1.3899 & 1.3899 & 1.3898 & 1.3897 \\
$\mathrm{C}(4)-\mathrm{C}(5)$ & 1.3980 & 1.3980 & 1.3982 & 1.3984 \\
$\mathrm{C}(5)-\mathrm{C}(6)$ & 1.4115 & 1.4111 & 1.4106 & 1.4101 \\
$\mathrm{C}(6)-\mathrm{C}(1)$ & 1.3982 & 1.3983 & 1.3985 & 1.3988 \\
$\mathrm{C}(2)-\mathrm{N}(8)$ & 1.3956 & 1.3946 & 1.3940 & 1.3937 \\
$\mathrm{~N}(8)-\mathrm{C}(13)$ & 1.3764 & 1.3774 & 1.3783 & 1.3793 \\
$\mathrm{~N}(9)-\mathrm{C}(13)$ & 1.3777 & 1.3779 & 1.3790 & 1.3801 \\
$\mathrm{~N}(9)-\mathrm{C}(3)$ & 1.3909 & 1.3902 & 1.3897 & 1.3894 \\
$\mathrm{C}(13)-\mathrm{C}(14)$ & 1.4093 & 1.4088 & 1.4076 & 1.4062 \\
$\mathrm{C}(14)-\mathrm{C}(15)$ & 1.3957 & 1.3928 & 1.3935 & 1.3946 \\
$\mathrm{C}(14)-\mathrm{C}(13)-\mathrm{N}(8)$ & 130.2 & 129.8 & 129.9 & 129.9 \\
$\mathrm{~N}(8)-\mathrm{C}(13)-\mathrm{C}(14)-\mathrm{C}(15)$ & 19.6 & 19.3 & 18.4 & 17.6 \\
\hline
\end{tabular}

" $n$ " is the number of carbon atoms.

length of the polymethine chain of the different carbocyanine dyes induces a bathochromic shift of the maximum absorption wavelengths about $100 \mathrm{~nm}$ for each addition of $\mathrm{C}_{2} \mathrm{H}_{4}$ group $[45,46]$.

The performance of TDDFT on the sulfur-organic dyes has been investigated by Fabian [47]. In that study the excited state calculations for the polymethine cyanine dyes with different chain lengths 
Table 7

Mulliken charges of cyanine dye derivatives with different polymethine chain.

\begin{tabular}{llrrr}
\hline $\begin{array}{l}l \\
\text { Group No. }\end{array}$ & \multicolumn{1}{l}{5} & \multicolumn{1}{l}{7} & \multicolumn{1}{l}{9} \\
\hline 1 & 0.283 & 0.282 & 0.280 & 0.278 \\
2 & 0.004 & -0.001 & -0.013 & -0.020 \\
3 & 0.268 & 0.271 & 0.271 & 0.272 \\
4 & 0.268 & 0.272 & 0.271 & 0.272 \\
5 & 0.004 & -0.001 & -0.013 & -0.020 \\
6 & 0.283 & 0.282 & 0.280 & 0.278 \\
7 & -0.110 & -0.101 & -0.079 & -0.054 \\
\hline
\end{tabular}

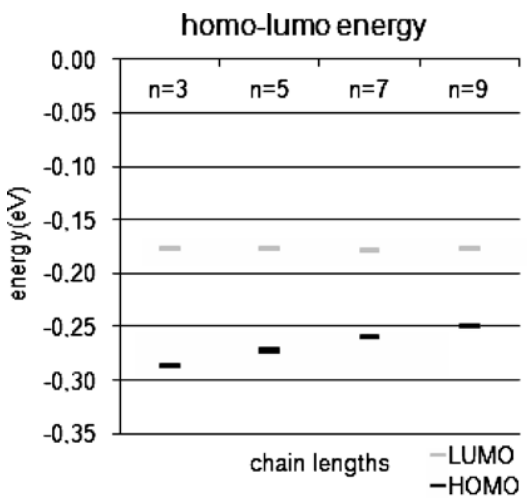

Fig. 13. HOMO-LUMO energies of cyanine dye derivatives with different polymethine chain.

are given. The bathochromic shift was found on the average as 63,76 and 94 with TDDFT, ZINDO/S and PPP per vinyl group, respectively.

The high oscillator strength corresponds to high intense peak. It was increased approximately 0.5 arbitrary units with elongation of the chain. The transition nature of $S_{0}$ to $S_{1}$ is mainly HOMO to LUMO. The second and all higher transitions have almost zero oscillator strengths (Table 8).
Table 8

The excited states compositions, oscillator strengths and $\lambda_{\max }$ of cyanine dye derivatives with different polymethine chain.

\begin{tabular}{lllcll}
\hline$n$ & $\begin{array}{l}\text { Exc. } \\
\text { state }\end{array}$ & $\begin{array}{l}\text { Transition } \\
\text { character }\end{array}$ & $\begin{array}{l}\text { Transition } \\
\text { probability }\end{array}$ & $\begin{array}{l}\text { Oscillator } \\
\text { strength }\end{array}$ & $\begin{array}{c}\lambda_{\max } \\
(\mathrm{nm})\end{array}$ \\
\hline 3 & $\mathrm{~S}_{1}$ & $\mathrm{H} ; \mathrm{L}$ & 0.62 & 1.89 & 433 \\
& $\mathrm{~S}_{2}$ & $\mathrm{H}-1 ; \mathrm{L}$ & 0.58 & 0.00 & 320 \\
& & $\mathrm{H} ; \mathrm{L}+1$ & 0.40 & & \\
5 & $\mathrm{~S}_{1}$ & $\mathrm{H} ; \mathrm{L}$ & 0.60 & 2.47 & 487 \\
& $\mathrm{~S}_{2}$ & $\mathrm{H}-1 ; \mathrm{L}$ & 0.54 & 0.00 & 348 \\
& & $\mathrm{H} ; \mathrm{L}+1$ & -0.45 & & \\
& & $\mathrm{~S} ; \mathrm{L}$ & 0.58 & 3.01 & 541 \\
& $\mathrm{~S}_{2}$ & $\mathrm{H}-1 ; \mathrm{L}$ & 0.52 & 0.00 & 381 \\
9 & & $\mathrm{H} ; \mathrm{L}+1$ & 0.47 & & 594 \\
& $\mathrm{~S}_{1}$ & $\mathrm{H}-1 ; \mathrm{L}+2$ & 0.11 & 3.51 & \\
& & $\mathrm{H} ; \mathrm{L}$ & 0.57 & & 420 \\
& $\mathrm{~S}_{2}$ & $\mathrm{H}-1 ; \mathrm{L}+1$ & 0.51 & 0.00 & \\
& & $\mathrm{H} ; \mathrm{L}+2$ & -0.48 & & \\
\hline
\end{tabular}

The HOMO-LUMO shapes are shown in Fig. 14 for the molecules with different size of polymethine chain. The electrons spread out on the backbone of the molecule. There is no electron density on ethyl groups which are perpendicular to molecular plane. The donor ability of the $\mathrm{Cl}$ atoms decrease as a result of elongation of the chain length. The electron density on $\mathrm{Cl}$ atoms gradually disappear from $n=3$ to $n=9$ in HOMO pictures. The $\pi, \pi$ nature of HOMO-LUMO were not affected by the lengthening.

\subsubsection{Effect of length of alkyl groups}

In this part, the effect of the size of the alkyl groups attached to nitrogen atoms was investigated. The $\mathrm{X}$ groups in Fig. 15 were changed as hydrogen, methyl, ethyl, propyl and butyl groups.

Although there is no considerable change on the bond lengths and angles by the alkyl size, the dihedral angle between benzimidazole ring and polymethine chain is significantly changed; hydrogen, propyl, butyl containing molecules are planar but methyl and ethyl substituted ones have twisted about $20^{\circ}$ (Table 9 ).

Almost all the positive charges are on the alkyl groups for all derivatives, each alkyl has around +0.3 charge. The benzimidazole

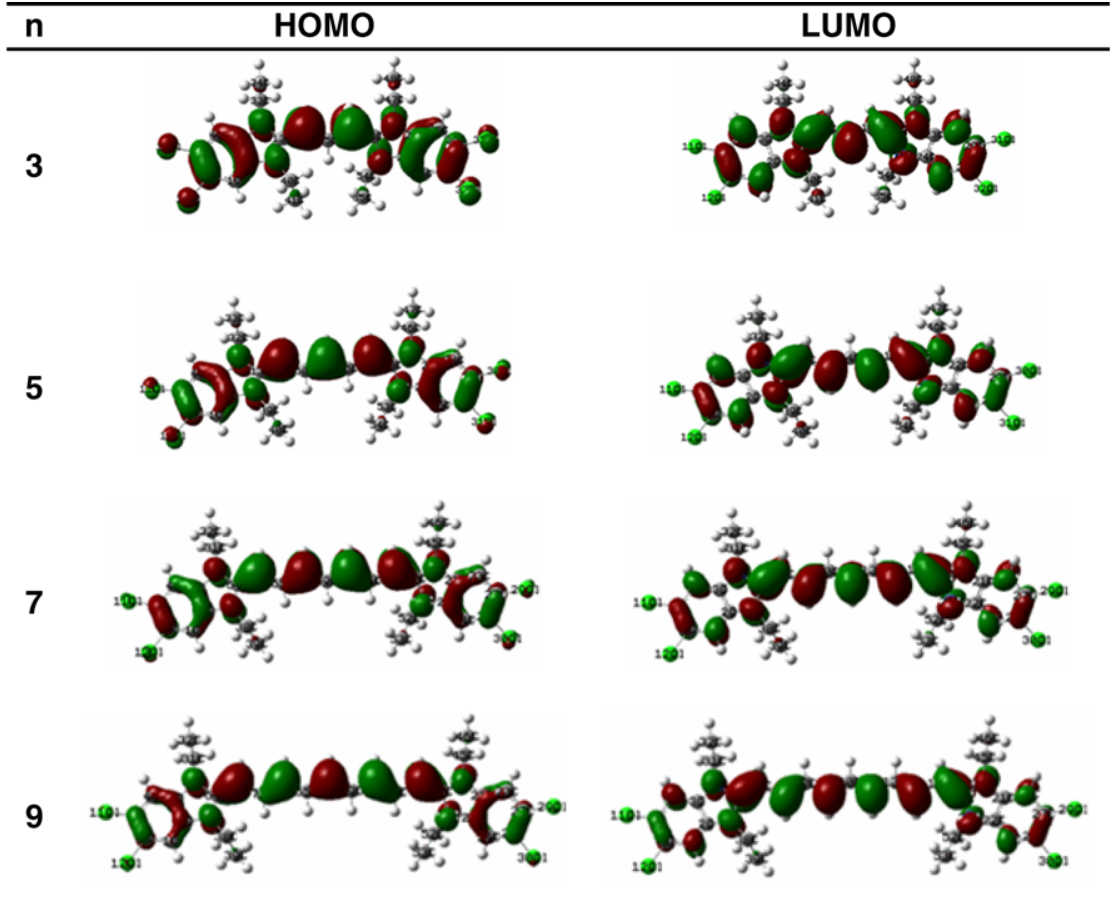

Fig. 14. HOMO-LUMO figures of cyanine dye derivatives with different polymethine chain. 


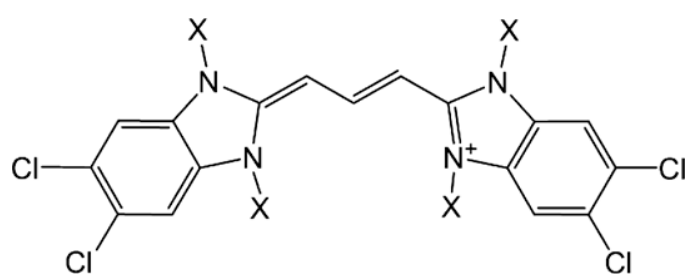

Fig. 15. Cyanine dye derivatives with different alkyl groups.

Table 9

Geometrical parameters of the dye derivatives with different alkyl groups.

\begin{tabular}{llllll}
\hline Atoms & Hydrogen & Methyl & Ethyl & Propyl & Butyl \\
\hline $\mathrm{C}(1)-\mathrm{C}(2)$ & 1.3869 & 1.3889 & 1.3894 & 1.3897 & 1.3897 \\
$\mathrm{C}(2)-\mathrm{C}(3)$ & 1.4032 & 1.4015 & 1.4007 & 1.4005 & 1.4006 \\
$\mathrm{C}(3)-\mathrm{C}(4)$ & 1.3874 & 1.3894 & 1.3899 & 1.3901 & 1.3901 \\
$\mathrm{C}(4)-\mathrm{C}(5)$ & 1.3985 & 1.3978 & 1.3980 & 1.3976 & 1.3976 \\
$\mathrm{C}(5)-\mathrm{C}(6)$ & 1.4130 & 1.4119 & 1.4115 & 1.4108 & 1.4107 \\
$\mathrm{C}(6)-\mathrm{C}(1)$ & 1.3988 & 1.3981 & 1.3982 & 1.3980 & 1.3980 \\
$\mathrm{C}(2)-\mathrm{N}(8)$ & 1.3956 & 1.3963 & 1.3956 & 1.3964 & 1.3962 \\
$\mathrm{~N}(8)-\mathrm{C}(13)$ & 1.3684 & 1.3755 & 1.3764 & 1.3787 & 1.3786 \\
$\mathrm{~N}(9)-\mathrm{C}(13)$ & 1.3673 & 1.3743 & 1.3777 & 1.3806 & 1.3806 \\
$\mathrm{~N}(9)-\mathrm{C}(3)$ & 1.3929 & 1.3923 & 1.3909 & 1.3904 & 1.3901 \\
$\mathrm{C}(13)-\mathrm{C}(14)$ & 1.4013 & 1.4082 & 1.4093 & 1.4080 & 1.4079 \\
$\mathrm{C}(14)-\mathrm{C}(15)$ & 1.3908 & 1.3946 & 1.3957 & 1.3954 & 1.3954 \\
$\mathrm{C}(14)-\mathrm{C}(13)-\mathrm{N}(8)$ & 129.3 & 129.3 & 130.2 & 131.0 & 131.0 \\
$\mathrm{~N}(8)-\mathrm{C}(13)-\mathrm{C}(14)-\mathrm{C}(15)$ & 0.0 & 21.7 & 19.6 & -1.7 & -1.5 \\
\hline
\end{tabular}

rings have around zero charges whereas the polymethine chain negatively charged. If deviation from planarity is observed then the charge on the benzimidazole changed from negative to positive and the charge on the chain becomes more negative (Table 10).

The dipole moments of the dye molecules decreased from hydrogen $(5.5 \mathrm{D})$ to butyl $(2.5 \mathrm{D})$ group. If we compare dipoles of the derivatives with consecutive alkyl size, the largest difference is observed in dipoles between methyl (4.7 D) and ethyl (3.5 D) substituted derivatives. The dyes with propyl $(2.8 \mathrm{D})$ and butyl groups have almost similar dipoles. The change in dipoles is only $3 \mathrm{D}$ from hydrogen to butyl.

Both $E_{\mathrm{LUMO}}$ and $E_{\mathrm{HOMO}}$ were slightly increased up to ethyl then remain same. HOMO-LUMO gap did not change much (Fig. 16).

Hydrogen and methyl substituted dye derivatives have $\lambda_{\max }$ values around $420 \mathrm{~nm}$ in Table 11 . The $\lambda_{\max }$ increased $10 \mathrm{~nm}$ for ethyl and another $10 \mathrm{~nm}$ increase is observed for propyl and butyl ( $\lambda_{\text {but }} \approx \lambda_{\text {pro }}>\lambda_{\text {eth }}>\lambda_{\text {met }} \approx \lambda_{\text {hyd }}$ ).

There is an experimental study about the synthesis and UV/Vis spectra of monomers and J-aggregates of 5,5',6,6'-tetrachlorobenzimidacarbocyanine dyes [48]. The only difference of these dyes with TTBC is the alkyl groups. The ethyl groups in TTBC replaced by alkyl groups or acidoalkyls or sulfoalkyls systematically. In all series the absorption and emission wavelengths did not change much. However, none of these dyes include the same moi-

Table 10

Mulliken charges of cyanine dye derivatives with different alkyl groups.

\begin{tabular}{lrrrrr}
\hline $\begin{array}{l}\text { X } \rightarrow \\
\text { Group No. }\end{array}$ & Hydrogen & Methyl & Ethyl & Propyl & \multicolumn{1}{c}{ Butyl } \\
\hline 1 & & & & & \\
\hline & 0.300 & 0.278 & 0.283 & 0.296 & 0.299 \\
3 & -0.062 & 0.011 & 0.004 & -0.026 & -0.031 \\
4 & 0.289 & 0.261 & 0.268 & 0.282 & 0.285 \\
5 & 0.289 & 0.261 & 0.268 & 0.282 & 0.285 \\
6 & -0.062 & 0.011 & 0.004 & -0.026 & -0.031 \\
7 & 0.300 & 0.278 & 0.283 & 0.296 & 0.299 \\
\hline
\end{tabular}

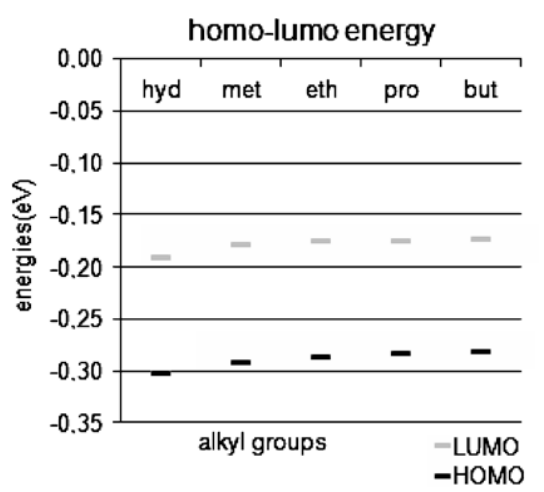

Fig. 16. HOMO-LUMO energies of cyanine dye derivatives with different alkyl groups.

Table 11

The excited states compositions, oscillator strengths and $\lambda_{\max }$ of cyanine dye derivatives with different alkyl groups.

\begin{tabular}{lllcll}
\hline Alkyl groups & Exc. state & $\begin{array}{l}\text { Transition } \\
\text { character }\end{array}$ & $\begin{array}{l}\text { Transition } \\
\text { probability }\end{array}$ & $\begin{array}{l}\text { Oscillator } \\
\text { strength }\end{array}$ & $\lambda_{\text {max }}(\mathrm{nm})$ \\
\hline Hydrogen & $\mathrm{S}_{1}$ & $\mathrm{H} ; \mathrm{L}$ & 0.61 & 2.00 & 422 \\
& $\mathrm{~S}_{2}$ & $\mathrm{H}-1 ; \mathrm{L}$ & 0.65 & 0.02 & 325 \\
& & $\mathrm{H} ; \mathrm{L}+1$ & -0.22 & & \\
Methyl & $\mathrm{S}_{1}$ & $\mathrm{H} ; \mathrm{L}$ & 0.62 & 1.90 & 424 \\
& $\mathrm{~S}_{2}$ & $\mathrm{H}-1 ; \mathrm{L}$ & 0.61 & 0.00 & 319 \\
& & $\mathrm{H} ; \mathrm{L}+1$ & 0.34 & & \\
Ethyl & $\mathrm{S}_{1}$ & $\mathrm{H} ; \mathrm{L}$ & 0.62 & 1.89 & 433 \\
& $\mathrm{~S}_{2}$ & $\mathrm{H}-1 ; \mathrm{L}$ & 0.58 & 0.00 & 320 \\
& & $\mathrm{H} ; \mathrm{L}+1$ & 0.40 & & \\
Propyl & $\mathrm{S}_{1}$ & $\mathrm{H} ; \mathrm{L}$ & 0.62 & 1.87 & 442 \\
& $\mathrm{~S}_{2}$ & $\mathrm{H}-1 ; \mathrm{L}$ & 0.61 & 0.00 & 322 \\
& & $\mathrm{H} ; \mathrm{L}+1$ & 0.35 & & \\
Butyl & $\mathrm{S}_{1}$ & $\mathrm{H} ; \mathrm{L}$ & 0.62 & 1.83 & 443 \\
& $\mathrm{~S}_{2}$ & $\mathrm{H}-1 ; \mathrm{L}$ & 0.60 & 0.00 & 321 \\
& & $\mathrm{H} ; \mathrm{L}+1$ & -0.36 & & \\
\hline
\end{tabular}

eties on the four nitrogens. Pairs of the same alkyl containing groups are used for each dye molecule on the nitrogens.

The transition nature to the first excited state is again HOMO to LUMO with high oscillating strength. The higher transitions are almost forbidden (Table 11).

The alkyl groups did not affect the HOMO and LUMO shapes as shown in Fig. 17.

\section{Conclusion}

In this work, the effects of functional groups substituted to the benzene rings, length of the conjugated chain and the size of alkylgroups bonded to the nitrogen atoms on the ground and excited state properties of the TTBC have been analyzed.

There is no significant effect of functional groups either as donor or acceptor on the molecular skeleton structure of TTBC. Only the alkyl groups attached to nitrogen atoms change the planarity of the molecule. If hydrogen, propyl and butyl groups are used instead of ethyl moieties then the molecule becomes planar.

Electron donor and acceptor substituents increases $\lambda_{\max }$ with respect to TTBC. If strong electron donor groups are attached to benzimidazole ring instead of chlorines then $\lambda_{\max }$ increases about $30 \mathrm{~nm}$. Similarly, if two $\mathrm{NO}_{2}$ electron acceptors bonded to different benzimidazole rings, the $\lambda_{\max }$ shifted by about $20 \mathrm{~nm}$ as well. This can be explained as, they participate in electron delocalization. However, if they joined to the same benzene ring, they strongly induce electron acceptor property and cause to decrease molecular conjugation. 


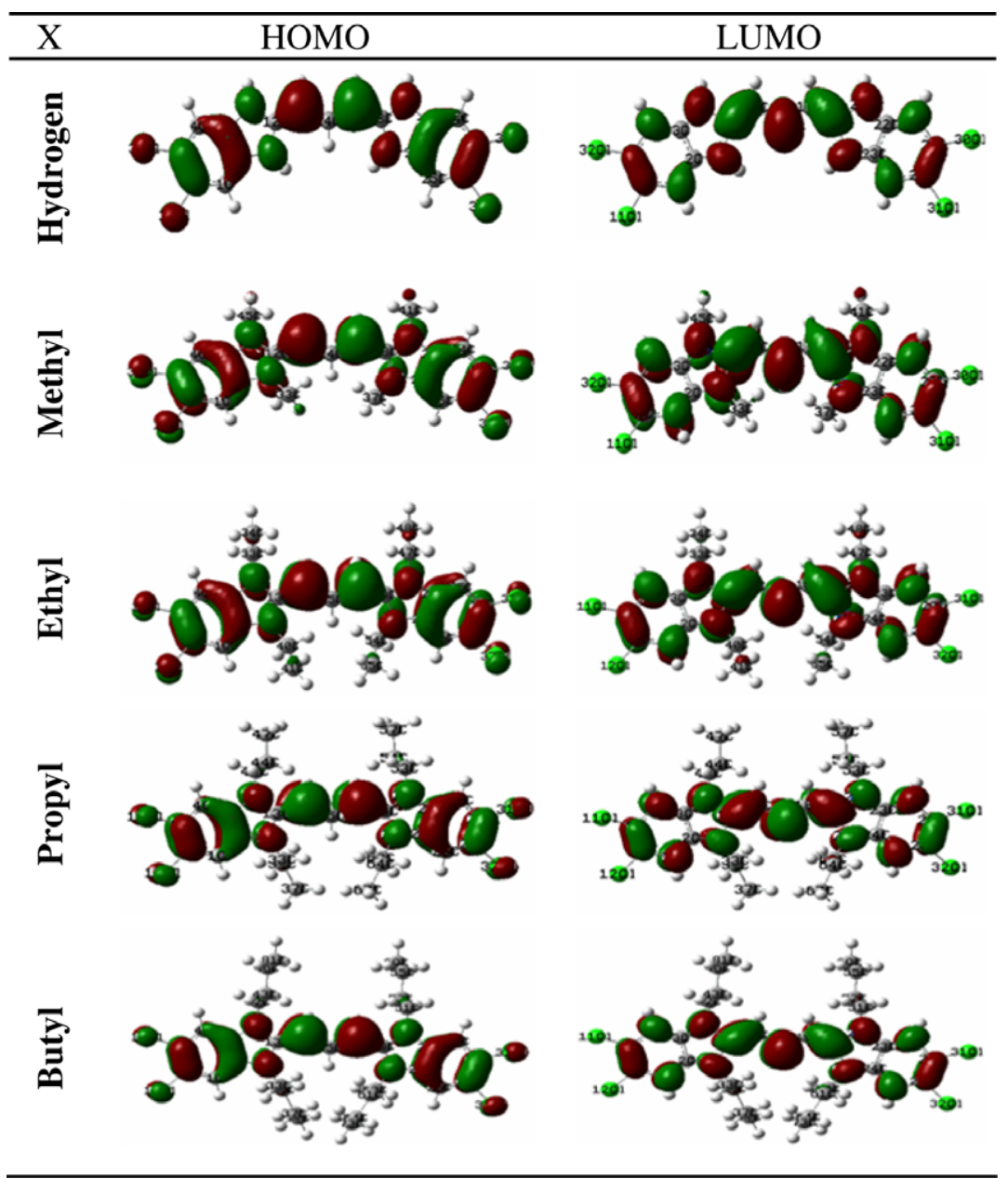

Fig. 17. HOMO-LUMO figures of cyanine dye derivatives with different alkyl groups

Increasing the conjugation length by one vinyl group increases $\lambda_{\max }$ by $50 \mathrm{~nm}$. The HOMO energies increase linearly with the chain length whereas LUMO does not change. Alkyl size may also shift $\lambda_{\max }$, for butyl and propyl compared to ethyl, the difference is $10 \mathrm{~nm}$.

In summary, TTBC has a very rigid geometry. However, it is possible to tune up $\lambda_{\max }$ with $\mathrm{NH}_{2}$ substituents on the benzimidazole rings, butyl/propyl groups bonded to nitrogens and increasing polymethine chain length.

We hoped that with the help of this study the properties of the TTBC at the ground and excited state could be understand easily and give insight into the design of the synthesis of new dye derivatives.

\section{References}

[1] A. Mishra, R.K. Behera, P.K. Behera, B.K. Mishra, G.B. Behera, Chem. Rev. 100 (2000) 1973.

[2] J.F. Hamilton, in: T.H. James (Ed.), The Theory of the Photographic Process, fourth ed., Macmillan, New York, 1977, p. 235.

[3] F.P. Schäfer, Dye Lasers, third ed., Springer-Verlag, New York, 1990.

[4] T.G. Pavlopoulos, in: H.S. Freeman, A. Peters (Eds.), Laser Dye Structure and Spectroscopic Properties, Colorants for Non-Textile Applications, Elsevier, Amsterdam, 2000, p. 274.

[5] M. Kawakami, K. Koya, T. Ukai, N. Tatsuta, A. Ikegawa, K. Ogawa, T. Shishido, L.B. Chen, J. Med. Chem. 41 (1998) 130

[6] M. Furuki, O. Wada, L.S. Pu, L.Y. Sato, H. Kawashima, T. Tani, J. Phys. Chem. B 103 (1999) 7607

[7] P. Chen, S. Sun, Y. Hu, Z. Qian, D. Zheng, Dyes Pigments 41 (1999) 227.

[8] R.P. Haugland, Handbook of Fluorescent Probes and Research Chemicals, fifth ed., Molecular Probes, Eugene, OR, 1992.
[9] S. Smiley, M. Reers, H.C. Mottola, M. Lin, A. Chen, T.W. Smith, G.D. Steele Jr., L.B Chen, Proc. Natl. Acad. Sci. USA 88 (1991) 3671.

[10] A. Cossarizza, C.M. Baccarani, G. Kalashnikova, C. Franchesci, Biochim. Biophys. Res. Commun. 197 (1993) 40

[11] E.E. Jelley, Nature 138 (1936) 1009.

[12] M. Reers, T.W. Smith, L.B. Chen, Biochemistry 30 (1991) 4480.

[13] E. Simeonova, M. Garstka, J. Kozioł-Lipińska, A. Mostowska, Protoplasma 223 (2004) 143.

[14] A.S. Waggoner, Cyanine Dyes as Labeling Reagents for Detection of Biological and Other Materials by Luminescence Methods, US Patent 6,956,032 Bl, October 18, 2005.

[15] E. Runge, E.K.U. Gross, Phys. Rev. Lett. 52 (1984) 997.

[16] M.A.L. Marques, E.K.U. Gross, Annu. Rev. Phys. Chem. 55 (2004) 427.

[17] M.E. Casida, in: D.P. Chong (Ed.), Recent Advances in Density Functional Methods, Part I, World Scientific, Singapore, 1995, p. 155

[18] M. Guillaume, V. Liegéois, B. Champagne, F. Zutterman, Chem. Phys. Lett. 446 (2007) 165.

19] B. Champagne, M. Guillaume, F. Zutterman, Chem. Phys. Lett. 425 (2006) 105.

[20] E. Perpète, F. Maruel, D. Jacquemin, J. Phys. Chem. A 111 (2007) 5528.

[21] M.C.R. Delgado, V. Hernandez, J. Casado, J.T.L. Navarrete, J. Mol. Struct (THEOCHEM) 709 (2004) 187

[22] D. Jacquemin, J. Preat, V. Wathelet, E.A. Perpète, Chem. Phys. 328 (2006) 324

[23] D. Jacquemin, J. Preat, V. Wathelet, M. Fontaine, E.A. Perpète, J. Am. Chem. Soc. 128 (2006) 2072.

[24] D. Jacquemin, E.A. Perpète, G. Scalmani, M.J. Frisch, X. Assfeld, I. Ciofini, C. Adamo, J. Chem. Phys. 125 (2006) 164324

[25] A. Dreuw, M.H. Gordon, J. Am. Chem. Soc. 126 (2004) 4007

[26] D.J. Tozer, R.D. Amos, N.C. Handy, B.O. Roos, L.S. Andrès, Mol. Phys. 97 (1999) 859 .

[27] T. Stein, L. Kronik, R. Baer, J. Am. Chem. Soc. 131 (2009) 2818.

[28] D.J. Tozer, N.C. Handy, Phys. Chem. Chem. Phys. 2 (2000) 2117

[29] S. Hirata, M.H. Gordon, Chem. Phys. Lett. 302 (1999) 375.

[30] N.T. Maitraa, F. Zhang, R. Cave, K. Burke, J. Chem. Phys. 120 (2004) 5932

[31] D.J. Tozer, N.C. Handy, J. Chem. Phys. 109 (1998) 10180.

[32] S. Hirata, C.G. Zhan, E. Aprá, T.L. Windus, D.A. Dixon, J. Phys. Chem. A 107 (2003) 10154. 
[33] D. Jacquemin, E.A. Perpète, G.E. Scuseria, I. Ciofini, C. Adamo, J. Chem. Theory Comput. 4 (2008) 123.

[34] D. Jacquemin, J. Preat, V. Wathelet, E.A. Perpète, J. Chem. Phys. 124 (2006) 074104.

[35] D. Jacquemin, J. Preat, V. Wathelet, E.A. Perpète, J. Mol. Struct. (THEOCHEM) 731 (2005) 67.

[36] D. Jacquemin, J. Preat, E.A. Perpète, Chem. Phys. Lett. 410 (2005) 254.

[37] D. Guillaumont, S. Nakamura, Dyes Pigments 46 (2000) 85.

[38] L.Y. Wang, Q.W. Chen, G.H. Zhai, Z.Y. Wen, Z.X. Zhang, J. Mol. Struct. (THEOCHEM) 778 (2006) 15.

[39] C.A. Bertolino, A.M. Ferrari, C. Barolo, G. Viscardi, G. Caputo, S. Coluccia, Chem. Phys. 330 (2006) 52.

[40] X.H. Zhang, L.Y. Wang, G.H. Zhai, Z.Y. Wen, Z.X. Zhang, Bull. Korean Chem. Soc. 28 (2007) 2382.
[41] M.J. Frisch, G.W. Trucks, H.B. Schlegel, G.E. Scuseria, M.A. Robb, J.R. Cheeseman, et al., Gaussian 03, Revision E.01, Gaussian, Inc., Wallingford, CT, 2004.

[42] A.D. Becke, J. Chem. Phys. 98 (1993) 5648.

[43] D.L. Smith, H.R. Luss, Acta Crystallogr. B 28 (1972) 2793.

[44] L.Y. Wang, Q.W. Chen, G.H. Zhai, Z.Y. Wen, Z.X. Zhang, Dyes Pigments 72 (2007) 357

[45] N.I. Fisher, F.M. Hamer, Proc. R. Soc. Lond. Ser. A Math. Phys. Sci. 154 (1936) 703.

[46] A.D. Kachkovsky, N.V. Pilipchuk, V.V. Kurdyukov, A.I. Tolmachev, Dyes Pigments 70 (2006) 212.

[47] J. Fabian, Theor. Chem. Acc. 106 (2001) 199.

[48] A. Pawlik, A. Ouart, S. Kirstein, H.W. Abraham, S. Daehne, Eur. J. Org. Chem. (2003) 3065. 